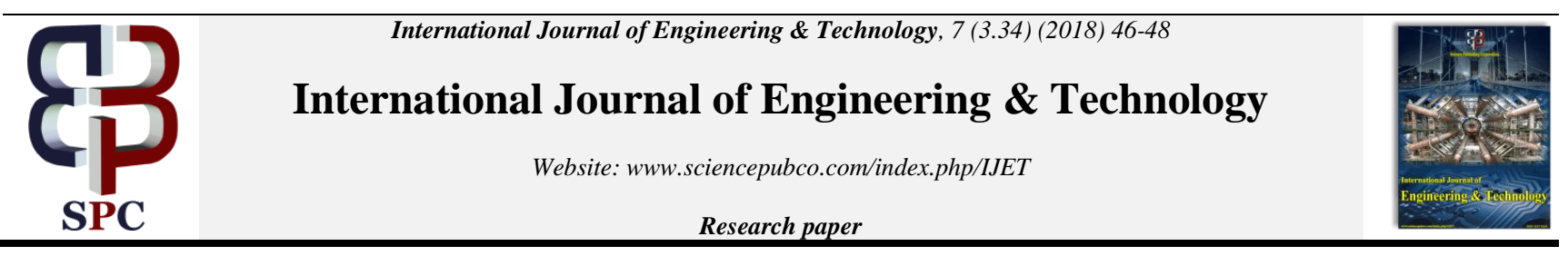

\title{
Design and Production of Portable Bar Bender
}

\author{
Mariyappan.K ${ }^{1^{*}}$, Karthick $\mathrm{N}^{2^{*}}$, Aasik Ahamed.N ${ }^{3^{*}}$, Gopinath.S ${ }^{4}$,Pradeep. $\mathbf{S}^{5}$, Suresh Kumar. $\mathrm{S}^{6}$, \\ 1,2,3,4,5 Department of Mechanical Engineering, Vel Tech High Tech Dr.Rangarajan Dr.Sakunthala Engineering College, \\ Chennai - 600062, India. \\ ${ }^{6}$ Department of Mechanical Engineering, Panimalar Polytechnic College, Chennai - 600029, India. \\ *Corresponding author E-mail: jkmari143@gmail.com
}

\begin{abstract} small scale construction based rod bending works.

\section{Introduction}

Rod bender is extensively used in the construction of buildings and fabricators. Due to heavy prices rod bending machines did not reach to small scale construction workers. The portable rod bender is designed for small scale constructional bending purpose which is also very portable, and adjustable. This bender is designed for comfort to multi power source like hydraulics \& pneumatics. This portable bender can be manufactured by a mild steel (MS) for handling the hydraulics \& pneumatics power. This design gives more efficient than other benders for low cost installation and maintenance cost. Less complicated parts. Simple bending and stress calculation gives a support for this design.
\end{abstract}

During this generation many projects and inventions are invented to reduce the man power, time, and difficulties of the work. But still some small types of works are only based on the man power because of the cost price of invention and difficult of handling of inventions. This designed and fabricated hydraulic bar bending equipment is used for bending rods, strips, angles, and bars. During some period a type of hydraulic rod bending machines only used on large scale and industrial works. In our type we simplified the design suitably for

Keywords: Material (MS), Modeling (AUTO CADD, CREO), Power (portable for customer), Type (portable),

\section{Working Principle}

We are going to design and develop metal bending machine i.e. a sheet and pipe roller with the help of a hydraulic bottle jack and rollers as shown in fig.(1).

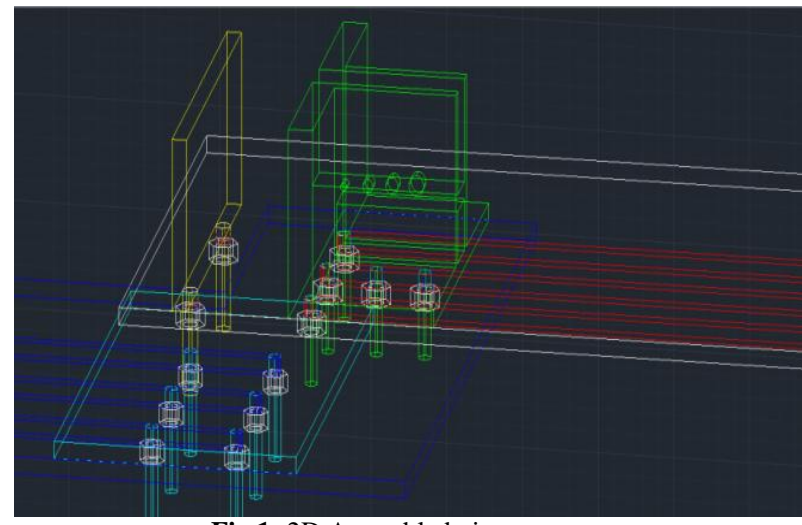

Fig 1: 2D Assembled view.
It consists of three rollers. One roller is at the upper frame and another two rollers are at the lower frame, and with the help of bottle jack force we will bend the metals. It has two MS square pipe frames one is fixed horizontally and other one vertically. At horizontal frame it consists of pedestal bearing through which shaft or roller rotates easily. At horizontal frame it has two rollers at parallel. At vertical frame it carries one more pedestal bearing and one roller through it. Hydraulic bottle jack is used to give motion to vertical frame by which we can apply gradual load while bending. Sheet is feed from these rollers, because of handle movement; this sheet is passed from rollers by rolling motion. We have to rotate handle by manually which is attached at roller of vertical frame.

\section{Methodology}

This portable bar bender working operation is based on hydraulics and pneumatics power by using energy conversion is hydraulic and pneumatic power converted to powerful reciprocating motion. In our design we have five main components namely

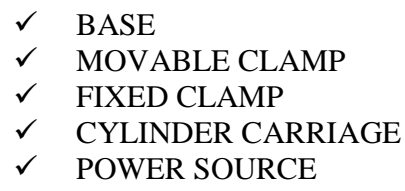

\subsection{Base:}

This base is a surface component of our design. The base part is made by "MS" (mild steel) inorder to withstand impact from work piece during bending operations. The base carries all of components of this portable bar bender hence it needs to withstand more impacts. This base part having slots for guiding movable clamp and cylinder carriage. 


\subsection{Movable Clamp:}

This is a major part of these bar bender which is made by "MS" (mild steel) . This movable clamp is used as a work holding device. This component only clamps the work piece for working operation. This clamp is fixed on a slot in the base for bending dimension settings. This movable clamp will also set the dimensions of the bending and holding of work piece.

\subsection{Fixed Clamp:}

This fixed clamp is a supporting component. This component only gives the support to the work piece. Hence it is made up of nonmetallic material. Based on load acting and cost.

\subsection{Cylinder Carriage:}

This component also has a main role on the bending operation. which is made by the same material of mild steel as because of load acting on this component by a slots, holes, and welded joints of design. This component is used to carry the hydraulic cylinder setup and carries it with the position of movable clamp location which also carries the cylinder and also travels with movable clamp size adjustments. And that only give a perfect bending on the rods, bars etc. In this setup it has a small amount of calculation position for slots and " $\mathrm{L}$ " cutting.

\subsection{Power Source:}

In this portable rod bender bars, rods etc. are bended by hydraulics and pneumatics both power source. As per customer use they will use the power as per their finance.

\subsection{Advantages:}

- $\quad$ The portable bar bending has less housing space compared then other hydraulic powered bar, rod benders.

- More efficient and simplified design.

- Maintenance cost is less.

\subsection{Applications:}

- This design will used for industrial rods, bar, strips bending applications.

- Mainly the design is used for bending contractual TMT rod bending process.

- If material properties and power source is increased this can be used on railway track bending applications too.

- The portable bar bender can be used on any platform at any temperature.

\section{Selection of material}

The material for this portable bar bender we select mild steel grade 70. "ASTM (American society for testing materials) 516"

\subsection{Properties of Mild Steel ASTM516:}

\subsubsection{Physical Properties:}

Density $=7.80 \mathrm{Gg} / \mathrm{cc}$

\subsubsection{Mechanical Properties:}

- $\quad$ Tensile strength, ultimate $=485-620 \mathrm{Mpa}$

- $\quad$ Tensile strength, yield $=260 \mathrm{Mpa}$
- $\quad$ Elongation of break $=17 \%$

- $\quad$ Modules of elasticity $=200 \mathrm{Gpa}$

- $\quad$ Bulk modules $=160 \mathrm{Gpa}$

- $\quad$ Poisson ratio $=0.29$

- $\quad$ Shear modules $=80.0 \mathrm{Gpa}$

\subsubsection{Thermal Properties:}

- Specific heat capacity $=0.470 \mathrm{~J} / \mathrm{g}-{ }^{\circ} \mathrm{C}$

- Thermal conductivity $=52.0 \mathrm{~W} / \mathrm{m}-\mathrm{K}$

\subsubsection{Elements Properties:}

\begin{tabular}{|l|l|}
\hline Carbon $(\mathbf{c})$ & 0.31 \\
\hline Iron $(\mathbf{F e})$ & 98.315 \\
\hline Manganese(Mn) & $0.85 \%$ to $1.2 \%$ \\
\hline Phosphorus $(\mathbf{P})$ & $0.035 \%$ \\
\hline Silicon $(\mathbf{S i})$ & $0.15 \%$ to $0.4 \%$ \\
\hline Sulfur(S) & $0.4 \%$ \\
\hline
\end{tabular}

\section{Design and Part Assembly}

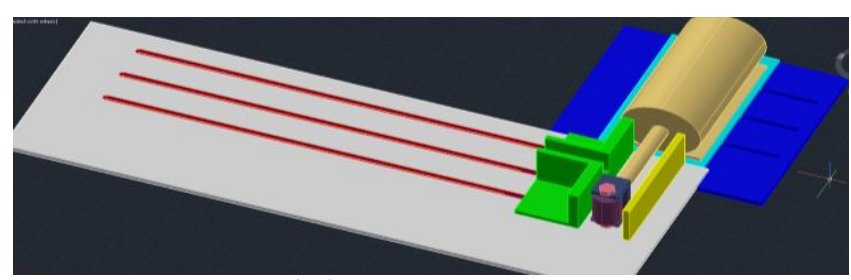

Fig 2: 3D assembled view.

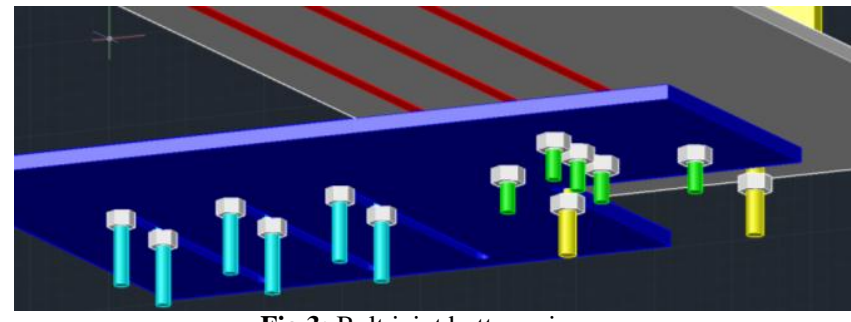

Fig 3: Bolt joint bottom view.

\section{Calculation}

In this design we need load to bend the TMT rods. The ultimate tensile stress and elongation for the TMT rod are given by the TMT manufactures in Table 1.

Table 1: Properties of TMT rod.

\begin{tabular}{|l|l|l|}
\hline \multicolumn{3}{|c|}{ Mechanical properties } \\
\cline { 2 - 3 } & \multicolumn{2}{|c|}{ Minimum value } \\
\cline { 2 - 3 } & FE 500 & FE 500D \\
\hline Yield stress $\left(\mathrm{N} / \mathrm{mm}^{2}\right)$ & 500 & 500 \\
\hline Ultimate tensile stress $\left(\mathrm{N} / \mathrm{mm}^{2}\right)$ & 545 & 585 \\
\hline UTS/YS Ratio & 1.08 & 1.1 \\
\hline \%Elongation & 12 & 16 \\
\hline
\end{tabular}

Hence, we have to choose the highest value of UTS $=580 \mathrm{~N} / \mathrm{mm}^{2}$

\subsection{Formulae:}

Stress $(\sigma)=\frac{P}{A} \mathrm{~N} / \mathrm{mm}^{2}$

Where,

Stress given $\left(580 \mathrm{~N} / \mathrm{mm}^{2}\right)$

$\mathrm{P}=\operatorname{load}$ in $(\mathrm{N})$ 
$\mathrm{A}=$ area of TMT rods in $\left(\mathrm{mm}^{2}\right)$

$\operatorname{Area}(A)=\frac{\pi}{4} \mathrm{~d}^{2} \mathrm{~mm}^{2}$

$\mathrm{d}=$ diameter of the TMT rods.

\subsection{Model Calculation:}

Example, Load need to bend for $5 \mathrm{~mm} \mathrm{~A}_{1}$ :

$\mathrm{A}_{1}=\frac{\pi}{4} \times 5^{2} \mathrm{~mm}^{2}$

$580=\frac{P}{19.63} \mathrm{~N} / \mathrm{mm}^{2}$

$\mathrm{P}=0.11 \mathrm{bar}$

Load need to bend the $5 \mathrm{~mm}$ TMT rod is $=\mathrm{P}_{1}>0.11 \mathrm{bar}$

\begin{tabular}{|l|l|l|}
\hline \multirow{3}{*}{ Rod diameter } & Need load for UTS of & Need load for UTS of \\
& $F_{e} 500$ & $F_{e} 500 \mathrm{D}$ \\
& $545 \mathrm{~N} / \mathrm{mm}^{2}$ & $580 \mathrm{~N} / \mathrm{mm}^{2}$ \\
\hline $5 \mathrm{~mm}$ & $0.11 \mathrm{bar}$ & $0.15 \mathrm{bar}$ \\
\hline $8 \mathrm{~mm}$ & $0.25 \mathrm{bar}$ & $0.35 \mathrm{bar}$ \\
\hline $10 \mathrm{~mm}$ & $0.4 \mathrm{bar}$ & $0.5 \mathrm{bar}$ \\
\hline $12 \mathrm{~mm}$ & $0.6 \mathrm{bar}$ & $0.7 \mathrm{bar}$ \\
\hline $15 \mathrm{~mm}$ & $0.8 \mathrm{bar}$ & $1.2 \mathrm{bar}$ \\
\hline
\end{tabular}

The load from cylinder it's may be more than $\underline{\mathbf{1 . 2 b a r}}$

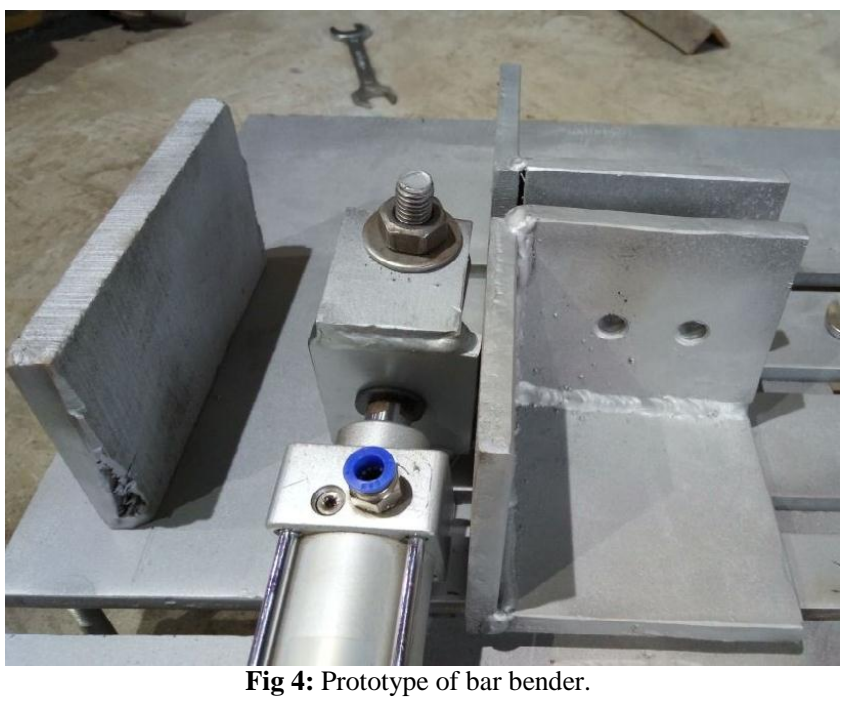

\section{Conclusion}

The hydraulic bar bender can be used on all types of bars, rods, bending processes. This is portable, low priced and customer user friendly. It can be carried anywhere easily. Easy to use and maintenance. The major drawback is if the bending diameters of the rod or bar exceed this equipment will get deflection or stroke of power source cylinder will break.

\section{Future Enhancement}

Existing hydraulic bending machines are manually operated and require no power consumption. It also has no maintenance cost and hence it makes cost effective, but when mass production is being carried out its manufacturing lead time and cycle time is very high. This makes it slower and requires some changes. Manually operated can be converted into electrically operated or pneumatic operated by using necessary equipments. This makes the device suitable for mass production. This reduces manufacturing lead time and cycle Time, but converting manual into automated system requires high initial cost and maintenance cost. It also becomes bulky and complex with the addition of new components. This method is useful as it increases the rate of production and finds extensive applications in automobile industries. Tubes can also be bent in automatic control. We measure the bends by using vernier caliper. In case of flat bend, the mandrel should be advanced.

\section{References}

[1] Thokale Manoj, Kothwal Satish, Kotkar Rahul, More Suyog, Pawase Mahesh "Design and Fabrication Of Pneumatic Bar Bending Machine" International Research Journal of Engineering and Technology (IRJET), Volume: 04, Issue: 03, Mar -2017, pp-14031406.

[2] Harshad Khairkar, Dhananjay Kopre, Saurabh Kalkar, Dipali Kambe, Sarang Gulhane, "Fabrication of Automatic Hydraulic Bending And Bend Removing Machine" International Research Journal of Engineering and Technology (IRJET), Volume: 04, Issue: 02, Feb -2017, PP-1343-1347.

[3] A. D.Zope, R.R.Deshmukh, D.R.Mete, V.S.Mane “ Review Paper on Design and Development of Metal Bending Machine" IOSR Journal of Mechanical and Civil Engineering (IOSR-JMCE) 6th National Conference RDME 2017, PP. 46-48.

[4] I.Muhammed Hanoofa, S.Ravi Vishwantha, P.Sureshkumara, N.Saravananb "Design and Fabrication of Hydraulic Rod Bending Machine" International Journal of Innovative Research in Science, Engineering and Technology, Volume 3, Special Issue 2, April 2014, PP. 237-241.

[5] Chetakraj Chavan, arjun Dhamale, Sharad Gaikwad, Gunjan Jawale Prof. S. G. Chitnis, "Design of Pipe Bending Machine” IOSR Journal of Mechanical and Civil Engineering (IOSR-JMCE), 1st National Conference On Recent Innovations in Mechanical Engineering (NCRIME-2018), PP. 52-56.

[6] R. Sanjay, S. SreyasAnand, Tamilselvan Senthilkumar, G. Vignesh, M. Sathish Kumar, "Design and Fabrication of Hydraulic Pipe BendingMachine" IJIRST, National Conference on Recent Advancements in Mechanical Engineering (RAME'17), PP.109-111.

[7] Thorave Rohit .V, "Design and Fabrication of Pipe Bending and Pipe Rolling Machine" International Journal of Advance Research, Ideas and Innovations in Technology, Volume 3, Issue 2, 2017, PP.561-565. 